\title{
More biologists but tenure stays static
}

It's official: biology postgraduates in the United States face greater competition for tenure than ever before. A wealth of data released this month will reopen discussions about employment and training in the US biomedical system.

The data, compiled by the Federation of American Societies for Experimental Biology (FASEB) (opa.faseb.org/pages/PolicyIssues/ training_datappt.htm), are from many sources, including the US National Science Foundation (NSF), the Council of Graduate Schools and the National Institutes of Health (NIH). And one message is clear: increasing numbers of bright young students are eager for a career in biology and biomedicine, but fewer than before will gain the coveted tenured academic positions.

NSF data show that the number of students in US graduate programmes in the biological sciences has increased steadily since 1966. In 2005, around 7,000 graduates earned a doctorate. But the number of biomedical $\mathrm{PhDs}$ with academic tenure has remained steady since 1981, at just over 20,000. During that period the percentage of US biomedical PhDs with tenure or tenuretrack jobs dropped from nearly $45 \%$ to just below $30 \%$.

So where do all the graduate students end up?

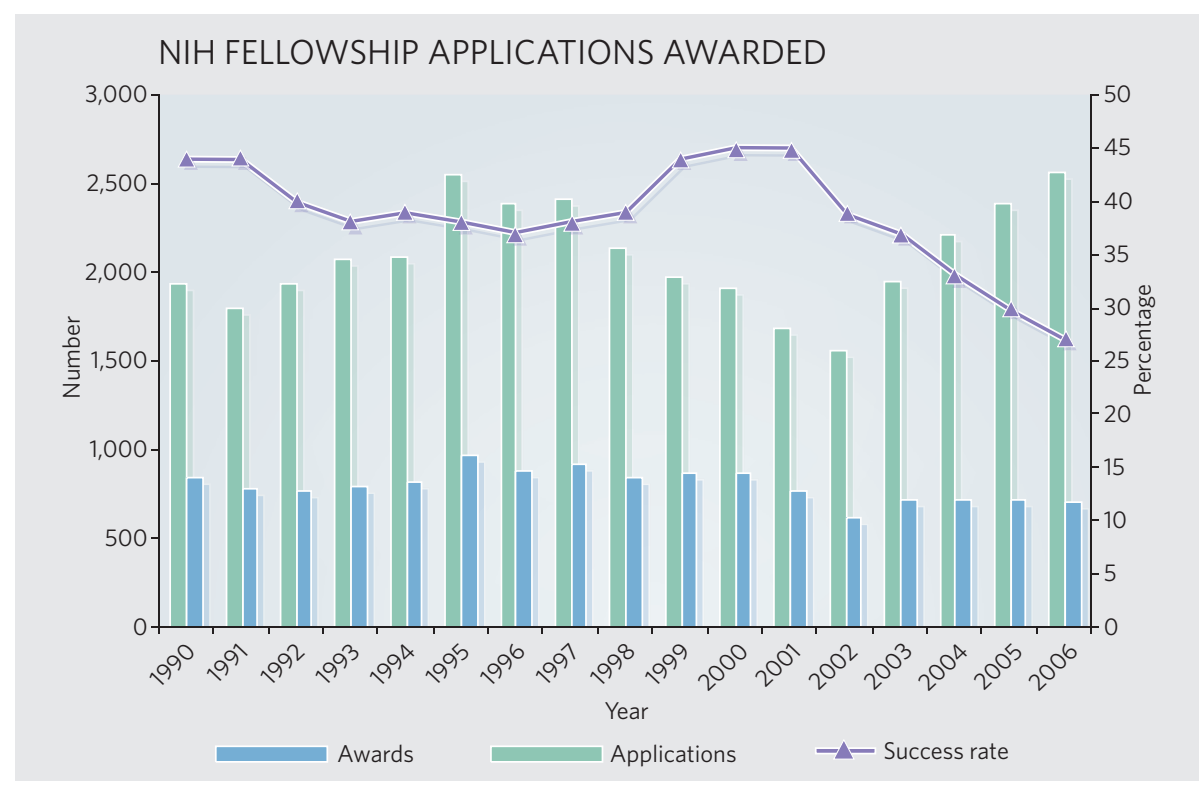

The percentage of biomedical $\mathrm{PhDs}$ going into industry has tripled, from $10 \%$ to $30 \%$, since the 1970s, the NSF reports. But those who stay on the academic track face a more arduous slog than their mentors. Although numbers of applicants for postdoctoral fellowships awarded by the NIH increased between 2002 and 2006, the percentage who were successful dropped sharply (see graphic above). And the average age of scientists earning their first R01 grant - the NIH's bread-

\section{Is baby DVD research Mickey Mouse science?}

The Walt Disney Company is going toe-to-toe with the University of Washington in Seattle after a study by the university's researchers suggested that exposure to DVDs and videos for babies, including Disney's Baby Einstein, could be associated with poorer language development.

One of the team, professor of paediatrics Dimitri Christakis, was widely quoted as saying "I would rather babies watch American Idol than these videos."

Robert Iger, Disney's chief executive, says the study's "methodology is doubtful, its data seem anomalous and the inferences it posits unreliable". In a letter to the university, he accused it of issuing a "deliberately misleading, irresponsible and derogatory" press release. "Whether your university is comfortable associating its name with analysis of this quality is, of course, your decision," he wrote. "And I would not be reaching out to you if all that was at stake was a poorly done academic study."

What is at stake is a milliondollar industry in such products for babies. A full set of Baby Einstein DVDs costs US $\$ 369.99$. Baby Einstein packaging says it "is not designed to make babies smarter", but detractors claim such products are marketed as educational.

"Disney is expecting the brand to bring in $\$ 1$ billion by 2010," says psychologist Susan Linn of Harvard Medical School in Boston, Massachusetts, and a founder of the Boston-based Campaign for a Commercial-Free Childhood, a group opposed to marketing to children. In May 2006 the campaign asked the US Federal Trade Commission (FTC) to investigate
Baby Einstein and Brainy Baby of Alpharetta, Georgia, another leading manufacturer of baby videos, for "engaging in deceptive acts and practices". They were backed by the American Academy of Pediatrics and the American Academy of Child and Adolescent Psychiatry. The complaint is still being considered.

Linn sees the entire 'baby industry' becoming more litigious. "We can expect more of this kind of corporate intimidation," she warns. "Disney is on the defensive and they're going to come out swinging."

The study, published online earlier this month (F. Zimmerman et al. J. Pediatr. doi:10.1016/ j.jpeds.2007.04.071; 2007), found that babies aged 8 to 16 months who watched such videos scored lower than other babies on the Communicative Development
Inventory (CDI), a standard tool used to gauge language development in infants. Babies that watched an hour a day scored 17 points lower on the CDI scale corresponding to knowing seven fewer words than a typical baby in the study who did not watch the videos, the researchers say.

Lead author Frederick

Zimmerman suggests several explanations for their findings, including the fact that parents worried about their child's language development might turn to the videos. But "it is possible that heavy viewing of baby DVDs/videos has a deleterious effect on early language development," he says.

The study was press-released by his university under the headline "Baby DVDs, videos may hinder, not help, infants' language development". University president 


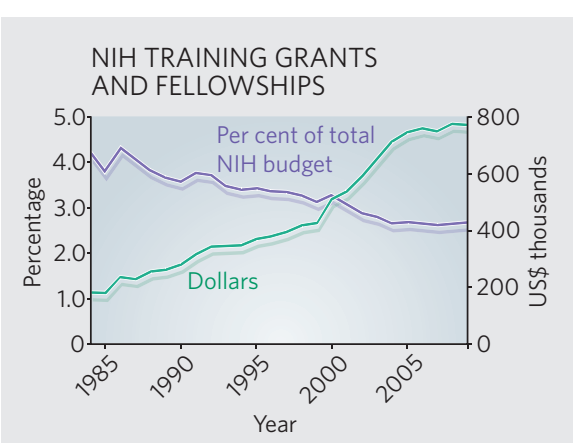

and-butter grant to an independent researcher has risen from 34 in 1970 to 42 now.

The percentage of $\mathrm{PhDs}$ still in a postdoctoral fellowship three or four years after their doctorate has declined since 1997, from $45 \%$ to $30 \%$, although the total number of postdocs grew from about 25,000 to 33,000 in the same period.

What does this mean for biology and biomedicine as a career option? It's more than an abstract question to Howard Garrison, director of FASEB's office of public affairs, who has a college-bound daughter. "She's thinking of biological sciences, so I tell her don't give up, but make sure you're realistic about your future," Garrison says. "People are drawn to the biological sciences because it's an exciting field and an exciting time, but people have to have a broad and flexible approach to their careers."

A huge question is why the doubling of the
NIH budget from 1998 to 2003 seems not to have helped young scientists. Most of the money went into infrastructure rather than tenure-track jobs (see Nature 443, 894; 2006). The NIH dollars devoted to training fellowships did grow, but not as fast as the rest of its budget, and when the NIH budget stopped growing, so did the dollars (see graphic on left).

Most NIH-supported postdoc appointments are now financed by research grants, not training grants. "If you're being supported to do research on research grants, but you're still a postdoc, there's a tension, because you're not being funded to be trained," says Jodi Lubetsky of the Association of American Medical Colleges.

Norka Ruiz Bravo, deputy director for extramural research at the NIH, says the agency welcomes the FASEB report: "FASEB has performed a very useful and timely service for the biomedical research community in highlighting this important issue. It is a matter of great interest and concern for NIH.” The NIH recently instituted the Pathways to Independence awards, which help postdocs set up their own labs.

A posting to an online careers discussion group puts the matter bluntly: "If you aren't thinking about 'alternative careers' before ever setting foot in graduate school, then you're being foolish."

\section{Erika Check}

See Editorial, page 839.

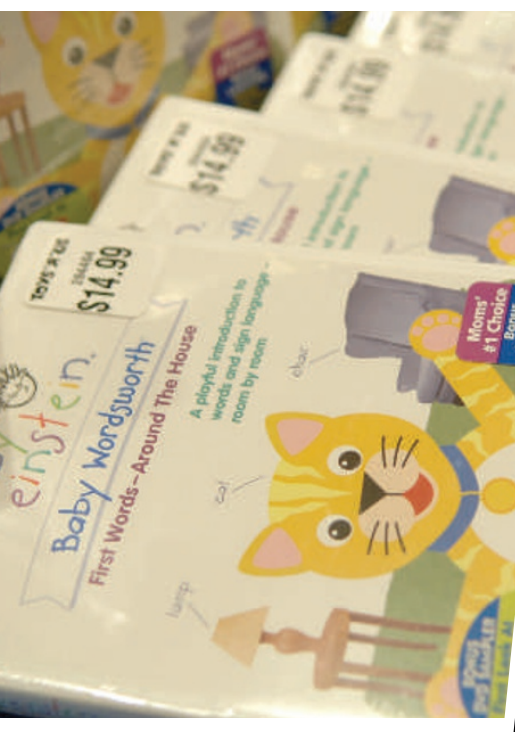

What babies watch: it may not make a difference.

Mark Emmert has refused to retract the press release and says he stands behind the research. "The findings were

aware of these findings," he says. Deborah Linebarger, an expert in child development and television at the University of Pennsylvania in Philadelphia, was asked by Disney to defend Baby Einstein to the FTC. Although believing such products can be useful, she declined. "I have concerns that anything called Baby Einstein, Genius, etcetera, is exploitive

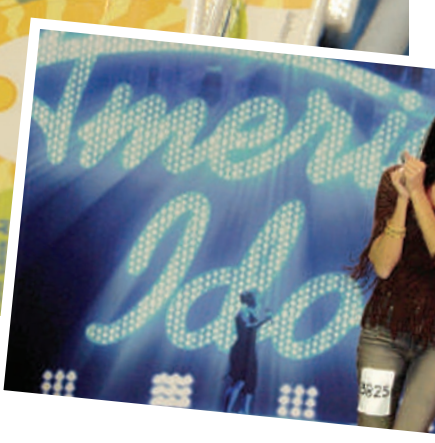

considered significant enough to be reported in a major journal, and as a public institution we feel duty bound to make the public of a vulnerable population," she says.

Despite having "some methodological issues" with the paper, she says: "There are some valid conclusions

in it that warrant
additional

44 in it that warran research. I'm cautious, but it makes sense."

Daniel Cressey
MICE CAN SMELL GREENHOUSE GAS Rising $\mathrm{CO}_{2}$ makes a stink for mice. www.nature.com/news

Let down by the statistics

Most claims that men and women are affected differently by disease-associated gene variations are poorly founded. A team of researchers has found that the data supporting such claims are often poorly analysed statistically or come from studies that were not adequately designed to show these links.

"The abysmal standard of statistical analysis in much of genetic epidemiology is little short of scandalous," says David Balding, professor of statistical genetics at Imperial College London, UK, who was not involved in the study. "This paper reveals an entire industry of prominently reported results that are largely unjustified and probably mostly false."

John Ioannidis and his colleagues at the University of Ioannina School of Medicine in Greece evaluated 432 claims in 77 research papers (N. Patsopoulos et al. J. Am. Med. Assoc. 298, 880-893; 2007). The team applied a set of criteria to determine whether the papers' authors had performed the correct analysis, such as comparing like with like, and had taken steps to show that the association was not due to chance. Worryingly, only $12.7 \%$ of claims satisfied these criteria. "There is quite a gap between what should have been done and what the journals and reviewers should have asked for, compared with what the authors did," says Ioannidis.

Many studies were not designed to test for a link between sex and gene variants, with researchers trying to extract associations from their data after the fact. Sample sizes were at least ten times smaller than they needed to be to yield statistically robust results, Ioannidis adds.

“This paper tells us that we don't have a clue whether gender is a real biomarker for any of the clinical areas assessed," says Howard McLeod, director of the UNC Institute for Pharmacogenomics and Individualized Therapy in Chapel Hill, North Carolina. "Gender, as well as age and race, are crude ways of understanding the complex factors regulating clinical effect," he adds. Claire Ainsworth 